\title{
The effectiveness of the use of the silicon- containing preparation Siliplant in the case of clonal micropropagation of the rose Reine Sammut
}

\author{
T.G. Lekontseva ${ }^{1, *}, A . V$. Fedorov ${ }^{1,2}, A . V$. Nikitina ${ }^{2}$, and A.M. Lentochkin ${ }^{2}$ \\ ${ }^{1}$ FSBSI Udmurt Federal Research Center of the Ural Branch of the Russian Academy of Sciences, \\ Izhevsk, Russia \\ ${ }^{2}$ FSBEI HE Izhevsk State Agricultural Academy, Izhevsk, Russia
}

\begin{abstract}
Clonal micropropagation of plants is a modern popular method of vegetative reproduction, which allows to obtain high-quality planting material in a large volume in a short time. The research is devoted to the technology of clonal micropropagation of the rose Reine Sammut, in particular, optimization of the nutrient medium composition. To increase the efficiency of micropropagation, the silicon-containing preparation Siliplant was added to the composition of the nutrient medium according to the Murashige-Skoog (MS) recipe as an alternative to the complex of trace elements. At the stage of the actual micropropagation with the combined use of 6-benzylaminopurine (6-BAP) at doses of $1.0 ; 2.0$ and $3.0 \mathrm{mg} / \mathrm{l}$ and Siliplant at doses of $1.0 ; 2.0$ and $3.0 \mathrm{ml} / 1$, no large differences were found. Nevertheless, the inclusion of Siliplant $(1.0 \mathrm{ml} / \mathrm{l})$ and 6 -BAP $(3.0 \mathrm{mg} / \mathrm{l})$ in the medium contributed to an increase in the reproduction factor by 3.1 $\mathrm{pcs}$. $/$ cuttings at $\mathrm{LSD}_{05}=1.0 \mathrm{pcs}$. In addition, Siliplant at a dose of $1.0 \mathrm{ml} / 1$ as part of a hormone-free nutrient medium MS contributed to a significant increase in shoot growth (by $4.2 \mathrm{~mm}$ at $\mathrm{LSD}_{05}=3.6$ ), and at a dose of 3.0 $\mathrm{ml} / 1$ stimulated the development of standard micro-plants of roses.
\end{abstract}

\section{Introduction}

The traditional method of propagation of roses is vegetative: cuttings, graftings, less often by layers. Nevertheless, these methods of reproduction are labor-intensive. An alternative method of producing planting material for roses is a biotechnological method of propagation. Most studies on clonal propagation of commercial rose varieties are aimed at optimizing the composition of nutrient media, selecting the composition of a mineral base with silicon-containing preparations that have a significant impact on the growth and development of plants propagated in vitro $[1,2]$.

\footnotetext{
${ }^{*}$ Corresponding author: t.lekontseva@yandex.ru
} 
According to I. V. Matychenkov [3], the main function of silicon in a plant is to increase resistance to adverse conditions, which is expressed in thickening of epidermal tissues (mechanical protection), accelerating growth, and strengthening the root system (physiological protection) and increasing resistance to abiotic stresses (biochemical protection). Plants absorb silicon in the form of ions $\left(\mathrm{SiO}_{3}{ }^{2-}\right)$ and $\left(\mathrm{SiO}_{4}{ }^{4-}\right)$, as well as in the form of monosilicon acids $\left(\mathrm{H}_{2} \mathrm{SiO}_{3}\right.$ and $\left.\mathrm{H}_{4} \mathrm{SiO}_{4}\right)$, which subsequently turn into silica gel $\mathrm{SiO}_{2} \times \mathrm{nH}_{2} \mathrm{O}$ in the cell juice. Then its biochemical binding with proteins and carbohydrates of the cell occurs, their accumulation on the surface of the cell walls, in the ground tissues (surface layers of the epidermis of leaves and roots, bark), or in various types of phytoliths (organo-mineral formations - globules that make up the ground and mechanical tissues of plants). The skeletal formation of the ground and conducting tissues of the plant, in fact, is accompanied by the formation of a double cuticular layer, which is a silica-cellulose membrane [4].

There are quite a lot of preparations that include silicon, and they are widely represented on the market: NV-101, Mival, Cherkaz, Melafen, Siliplant and many others. The preparation Siliplant, which had a positive effect on the adaptation of micro-plants of sweet-berry honeysuckle, wild strawberries, roses, grapes, was best studied during clonal micropropagation of plants $[5,6,1,7,8]$.

The purpose of the study was to study the effect of the silicon-containing preparation Siliplant in the MS nutrient medium on the effectiveness of clonal micropropagation of the rose Reine Sammut.

\section{Materials and methods}

The research was carried out in 2018-2020 on the basis of the laboratory of the Department of Plant Introduction and Acclimatization of the UdmFRC UrB RAS. The object of research was the micro-cuttings of the rose Reine Sammut (Guillot-Massad breeding, France).

Apical 2-4 bud segments of shoots with well-developed buds, selected in June, were used as initial explants for introduction into a sterile culture. In the laboratory, after removing the leaves and thorns, the cuttings were first washed with a soap solution, and then washed under running water for 30 minutes. The segments of shoots were sterilized in $0.1 \%$ sulema solution at an exposure of $4 \mathrm{~min}$ and $33.0 \%$ hydrogen peroxide solution ( 8 $\mathrm{min}$ ), followed by a five-fold washing with sterile distilled water. Explants were planted in test tubes with agarized nutrient medium MS, pH 5.6-5.8 [9], supplemented with 6-BAP at a concentration of $0.5 \mathrm{mg} / \mathrm{l}$. The cultivation of micro-cuttings was carried out in a light room at a temperature of $+25{ }^{\circ} \mathrm{C}$ with a photoperiod of 16 hours per day. The duration of each subcultivation was 30-35 days.

At the stage of actual micropropagation, rose cuttings were planted on MS medium supplemented with 6-BAP at a concentration of $1.0 ; 2.0$ and $3.0 \mathrm{mg} / \mathrm{l}$ (factor A) and Siliplant at doses of $1.0 ; 2.0$ and $3.0 \mathrm{ml} / 1$ (factor B) to obtain the maximum number of micro-shoots. There were 16 different media in total (Table 1). The preparation Siliplant was introduced into the composition of the nutrient medium before autoclaving.

During the research, the following parameters were determined: length of micro-shoots $(\mathrm{mm})$; reproduction factor (considered as the number of micro-shoots obtained for one subcultivation from one micro-cutting; pcs.); rooting success (the ratio of rooted cuttings to the total number of cuttings planted on the rooting medium; \%). The quality of the roots was assessed visually according to a three-point system: 1 point - underdeveloped root 
system with one main root or 2-3 shorter ones; 2 points - medium developed root system, 3-4 roots; 3 points - well-developed root system, 4-5 roots or more.

The experiments were carried out in three-fold repetition, 15-30 cuttings and plants were analyzed in each variant. Statistical data processing was performed by the method of variance analysis.

\section{Results and discussion}

According to the visual assessment, there was no difference in the development of explants depending on the reagent used for sterilization. After 14 days of cultivation on the MS medium with the addition of 6-BAP $(0.5 \mathrm{mg} / \mathrm{l})$, new shoots up to $10-20 \mathrm{~mm}$ long were observed without defects in development.

At the stage of micropropagation, the main task is to obtain the maximum number of micro-shoots of good quality without signs of vitrification, necrosis, chlorosis, etc. For this purpose, the composition of the nutrient medium according to the MS recipe was modified by introducing Siliplant instead of trace elements in doses of 1.0, 2.0 and $3.0 \mathrm{ml} / \mathrm{l}$.

The highest reproduction factor in the experiment was achieved in the variant with 6BAP at a dose of $1.0 \mathrm{mg} / 1$ (5.5 pcs.), significantly less than it was on hormon-free medium (1.3 pcs.) and on medium with 6-BAP at a dose of $3.0 \mathrm{mg} / 1(1,2 \mathrm{pcs}$. $)$ at $\mathrm{LSD}_{05}=1.0$. The obtained data are consistent with our previous studies and the data of other authors $[10,11]$.

For many rose varieties, the optimal concentration of 6 -BAP is $1.0 \mathrm{mg} / \mathrm{l}$, at which the optimal ratio of the quantity and quality of micro-cuttings is achieved. As our studies have shown, a higher content of 6-BAP contributes to the manifestation of vitrification and, as a result, the culling of micro-cuttings and a decrease in the reproduction efficiency (Figure 1).

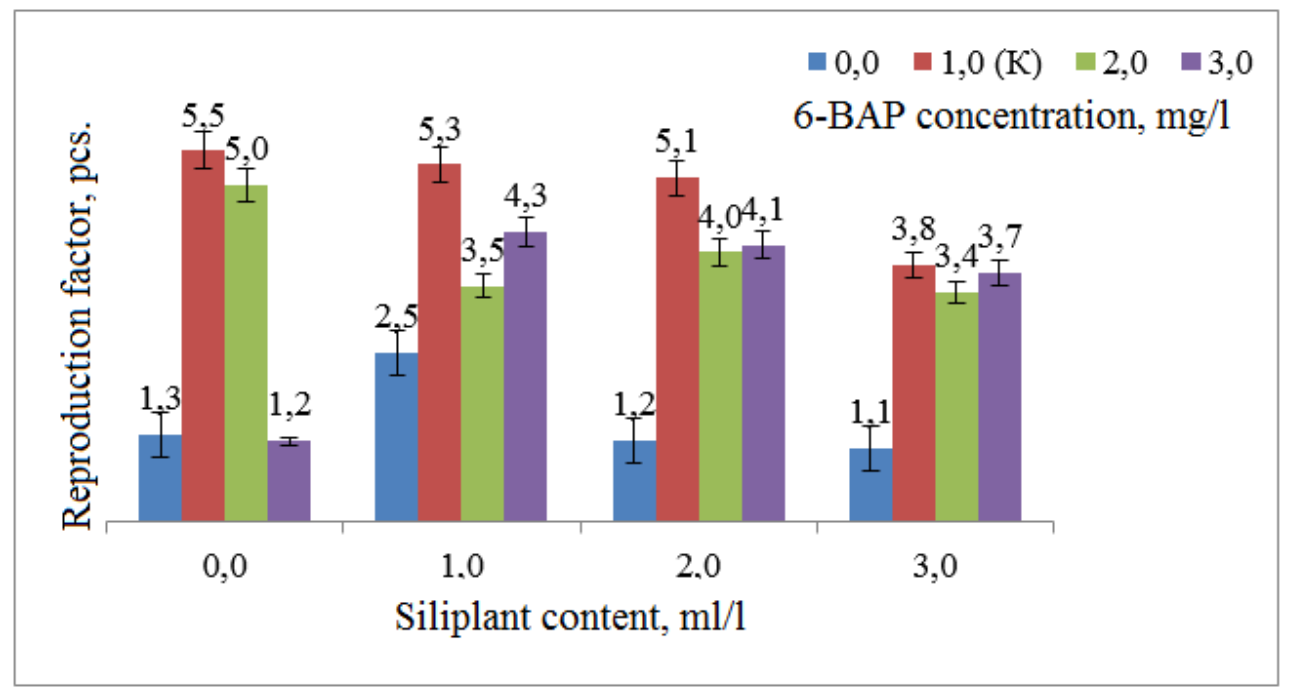

Fig. 1. The effect of Siliplant and 6-BAP on the reproduction factor of the rose Reine Sammut

On the hormone-free medium, the inclusion of Siliplant in the medium at a dose of 1.0 $\mathrm{ml} / 1$ contributed to a significant increase in the reproduction factor by $1.2 \mathrm{pcs}$./cutting (control -1.3 pcs.; $\mathrm{LSD}_{05}=1.0$ pcs.). Nevertheless, with a further increase in the dose of the preparation to 2.0 and $3.0 \mathrm{ml} / 1$, the reproduction factor decreased and was 1.2 and 1.1 pcs./cutting, respectively. 
The inclusion of Siliplant in the medium at a dose of $1.0 \mathrm{ml} / 1$ in combination with 6-BAP at a dose of $3.0 \mathrm{mg} / 1$ increased the reproduction factor by $3.1 \mathrm{pcs}$./cuttings at $\mathrm{LSD}_{05}$ $=1.0$ pcs. It can be assumed that the silicon contained in the Siliplant contributed to an increase in resistance to adverse factors to an increased content of 6-BAP and prevented the vitrification of shoots. Nevertheless, the reproduction factor was significantly lower compared to the control, which indicates that it is inappropriate to use high doses of cytokinin together with Siliplant.

The subsequent increase in Siliplant doses with all variants of cytokinin content in the nutrient medium and without it, the efficiency of micropropagation decreased.

The basic nutrient medium MS is characterized as rich, has two forms of nitrogen in its composition (ammonium and nitrate). It is used as a universal medium for clonal micropropagation of many plant species, but it is not recommended to use this medium for rooting.

According to our data, $80 \%$ of micro-cuttings took root on the complete hormone-free MS medium, the quality of root formation was on average at the level of 2.5 points (Figure 2 ). At the same time, the formation of long roots, which were dark in color, was observed, the leaves of the micro-plants bent down. Obviously, root formation became possible due to the endogenous synthesis of auxins by shoots.

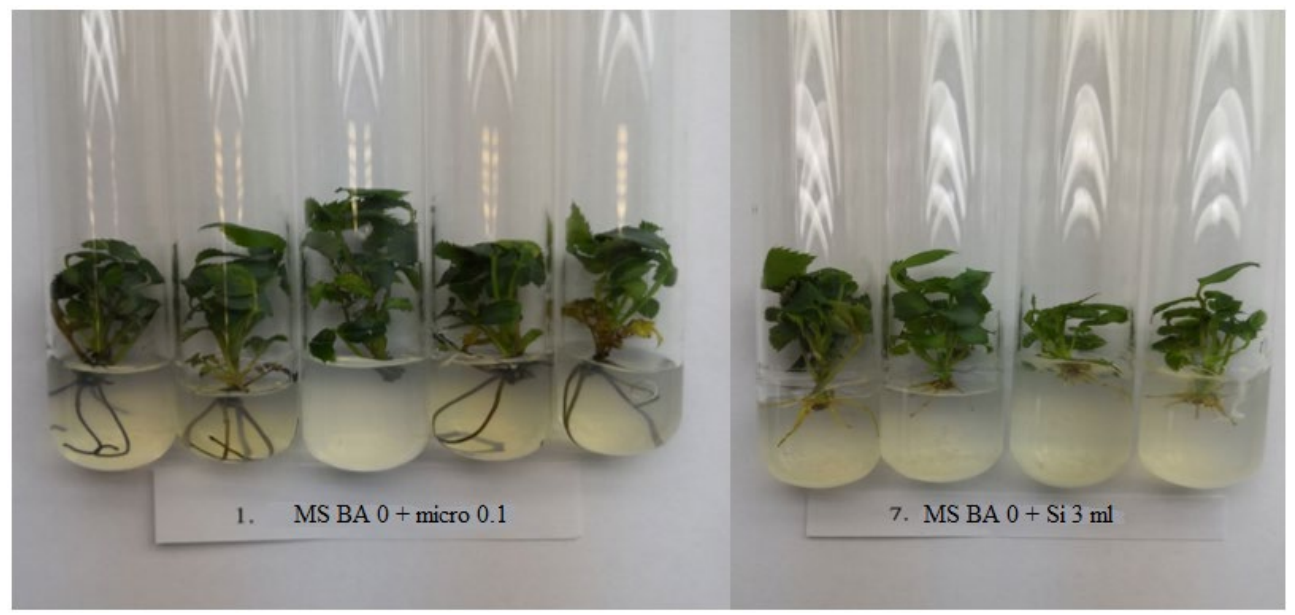

a)

b)

Fig. 2. Root formation of micro-cuttings of the rose Reine Sammut: a) on the hormone-free medium MS; b) on the hormone-free MS medium with Siliplant $3.0 \mathrm{ml} / 1$

In the nutrient medium in the variants with a Siliplant content of 2.0 and $3.0 \mathrm{ml} / \mathrm{l}$, the presence of flake-like white formations was noted, which, in our opinion, is associated with a high content of silicon in the solution.

On a medium with Siliplant at a dose of $3.0 \mathrm{ml} / 1,100 \%$ rooting of micro-cuttings was observed, the state of the root system averaged 2.5 points. The appearance of the microplants met the requirements (GOST 29105.2-91): the length of the main shoot is 2.0-5.0 $\mathrm{cm}$, the number of leaves is more than 4 , the number of roots is not less than 5 . This variant of the nutrient medium can be recommended for the root formation of micro-cuttings of roses, Reine Sammut, contrary to the prevailing idea of the need to use a depleted nutrient medium and auxins. 
Weak root formation was observed on media with Siliplant at a dose of 1.0 and $2.0 \mathrm{ml} / \mathrm{l}$, where 18.0 and $83.0 \%$ of micro-cuttings were rooted, the root quality was 1.0 and 2.3 points, respectively. On the hormone-free MS nutrient medium, the increase in microcuttings $(\Delta \mathrm{L})$ was equal to $8.9 \mathrm{~mm}$, with 6 -BAP at a dose of $1.0 \mathrm{mg} / \mathrm{l}-3.8 \mathrm{~mm}$. With a subsequent increase in the cytokinin concentration, the increase did not change significantly. These data fit into the generally accepted framework: the use of hormones removes apical dominance, stimulates the development of axillary kidneys.

The addition of Siliplant to the composition of the hormone-free medium at a dose of $1.0 \mathrm{ml} / 1$ stimulated a significant increase in shoot growth by $4.2 \mathrm{~mm}$ at $\mathrm{LSD}_{05}=3.6 \mathrm{~mm}$. With a subsequent increase in the Siliplant content, the value of $\Delta \mathrm{L}$ decreased (Table 1).

Table 1. Growth of micro-cuttings of the rose Reine Sammut $(\Delta \mathrm{L})$ depending on concentration of 6-BAP and Siliplant in the composition of the MS nutrient medium, mm.

\begin{tabular}{|c|c|c|c|c|c|c|c|}
\hline \multirow{2}{*}{\multicolumn{2}{|c|}{$\begin{array}{c}\text { Concentration } \\
6 \text {-BAP, mg/l } \\
\text { (factor A) }\end{array}$}} & \multicolumn{4}{|c|}{ Siliplant content, $\mathrm{ml} / \mathrm{l}$ (factor B) } & \multirow{2}{*}{$\begin{array}{c}\text { Average } \\
\text { for factor } \\
\text { A }\end{array}$} & \multirow[b]{2}{*}{ Deviation } \\
\hline & & $\begin{array}{l}\text { microelem. } \\
\text { for MS }(\mathrm{K})\end{array}$ & 1,0 & 2,0 & 3,0 & & \\
\hline \multicolumn{2}{|c|}{0.0} & 8.9 & 13.1 & 7,9 & 4,9 & 8,7 & $+6,3$ \\
\hline \multicolumn{2}{|c|}{$1.0(\mathrm{~K})$} & 3.8 & 2.7 & 1,3 & 1,7 & $2,4(\mathrm{~K})$ & - \\
\hline \multicolumn{2}{|c|}{2.0} & 1.3 & 2.5 & 0,5 & 0,0 & 1,4 & $-1,0$ \\
\hline \multicolumn{2}{|c|}{3.0} & 0.3 & 0.5 & 0,2 & 0,7 & 1,7 & $-0,7$ \\
\hline \multicolumn{2}{|c|}{ Average for factor B } & 3.6 & 4.7 & 2,5 & 2,4 & & \\
\hline \multicolumn{2}{|c|}{ Deviation } & - & +1.1 & $-1,1$ & $-1,2$ & & \\
\hline \multirow{3}{*}{$\mathrm{LSD}_{05}$} & \multicolumn{2}{|c|}{$\begin{array}{l}\text { particular } \\
\text { differences }\end{array}$} & & & \multicolumn{3}{|l|}{3.6} \\
\hline & \multicolumn{2}{|c|}{ factor $\mathrm{A}$} & & & \multicolumn{3}{|l|}{1.8} \\
\hline & \multicolumn{2}{|l|}{ factor B } & & & \multicolumn{3}{|l|}{1.5} \\
\hline
\end{tabular}

Our data are consistent with the results of research by E.V. Nemtsova et al. [12]. The use of amorphous silica in the composition of the Anderson nutrient medium at a dose of 50 $\mathrm{mg} / \mathrm{l}$ had a positive effect on the reproduction factor, shoot- and root formation of the aquarium plant Rotala indica.

\section{Conclusions}

1. The highest coefficient of micropropagation of one Reine Sammut rose cuttings on MS medium with the addition of 6-BAP at a dose of $1.0 \mathrm{mg} / 1$ was obtained on average $5.5 \mathrm{pcs}$. The addition of the silicon-containing preparation Siliplant in doses of 1.0-3.0 ml/1 in combination with 6-BAP in doses of $1.0-3.0 \mathrm{mg} / \mathrm{l}$ did not increase the reproduction factor. 2. At the stage of the actual micropropagation of the rose Reine Sammut, the joint use of 6BAP and Siliplant as part of the MS nutrient medium is impractical.

3. On the hormone-free nutrient medium, the use of Siliplant at a dose of $1.0 \mathrm{ml} / \mathrm{l}$ significantly increased the growth of rose micro-cuttings by $4.2 \mathrm{~mm}$ (control $-8.9 \mathrm{~mm}$; $\left.\mathrm{LSD}_{05}=3.6 \mathrm{~mm}\right)$.

4. Siliplant at a dose of $3.0 \mathrm{ml} / \mathrm{l}$ as part of a hormone-free complete nutrient medium MS provided $100 \%$ rooting of rose micro-cuttings. 


\section{References}

1. I.V. Mitrofanova, O.V. Mitrofanova, V.A. Brailko, N.P. Lesnikova-Sedoshenko, Izvestiya vuzov. Applied chemistry and biotechnology 2 (13), 37-48 (2015)

2. M.G. Markova, E.N, Somova, Agrarian science of the Euro-North-East 63 (2), 35-41 (2018)

3. I.V. Matychenkov, Mutual influence of silicon, phosphorus and nitrogen fertilizers in the soil-plant system: abstract of the dissertation of the candidate of Biological Sciences, 20 (Moscow : MSU, 2014)

4. A.V. Kozlov, H. Kulikova, E. A. Yashin, Bulletin of the Minin University 2(10), 23 (2015)

5. V.A. Vysotsky, V.A. Valikov, Fruit and berry growing in Russia, 38(1), 82-87 (2014)

6. N.A. Semenova, S.V. Akimova, O.N. Aladina, Fruit and berry growing in Russia 41, 325-329 (2015)

7. T.G. Lekontseva, A.V. Khudyakova, A.N. Isaeva, A.V. Fedorov, Bulletin of the Perm University, Biology series 3, 240-244 (2017)

8. A.N. Rebrov, Fruit growing and viticulture in the south of Russia 49 (1), 33-46 (2018)

9. T. Murashige, F. Skoog, Phisiologia plantarum 15, 437-497 (1962)

10. A.V. Khudyakova, T.G. Lekontseva, A.V. Fedorov, Bulletin of the VSU, series: biology, chemistry, pharmacy 2, 66-71 (2019)

11. N.A. Egorova, I.V. Stavtseva, I.V. Mitrofanova, Bulletin of the SSBS 120, 36-43 (2016)

12. E.V. Nemtsova, D.M. Novikov, T.P. Vykhor, Bulletin of the Bryansk branch of the RBA 3 (15), 42-48 (2018) 